ИЗВЕСТИЯ АҚАДЕМИИ НАУК ЭСТОНСКОИ ССР. ТОМ 30 ГЕОЛОГИЯ. 1981, № 4

\title{
ВЗАИМОСВЯЗЬ ЗАКОНОМЕРНОСТЕЙ РАСПРЕДЕЛЕНИЯ КОМПОНЕНТОВ В ФОСФОРИТАХ МЕСТОРОЖДЕНИЯ ТООЛСЕ С ИЗВЛЕЧЕНИЕМ ЗАПАСОВ
}

Изучение месторождений полезных ископаемых в целях установления кондиций на сырье, оконтуривания запасов и их геолого-экономической оценки связано с необходимостью выявления количественных закономерностей распределения полезного ископаемого в недрах и с геометризацией месторождений. Наиболее важными являются установление закономерностей между бортовым и средним содержаниями полезного компонента в руде, между бортовым содержанием, вынимаемой мощностью залежи и величиной балансовых запасов. В настоящей работе сделана попытка математически описать распределение полезного компонента в руде месторождения фосфоритов Тоолсе Эстонской ССР и установить связь между качеством добываемой руды и извлечением запасов.

Месторождение Тоолсе (Раудсеп, 1975) представлено почти горизонтальным пластом фосфоритоносных песчаников с включением обломков и реже целых раковин брахиопод при сравнительно выдержанной мощности пласта. Подстилающими породами являются тискреские песчаники. Содержание полезного компонента - пятиокиси фосфора по мощности пласта неравномерное и уменьшается от подошвы к кровле практически доо нуля. Таким образом, промышленная пачка постепенно замещается непромышленной толщей песчаников, перекрываемой пластом битуминозного тонкослоистого аргиллита. Такой характер распределения полезного компонента по мощности пласта предопределяет необходимость установления верхней границы выемки на основе опробования в зависимости от принятого бортового содержания, которое становится важнейшим кондиционным параметром, определяющим извлечение общих запасов месторождения и технико-экономические показатели добычи и переработки руды.

Исследование количественной закономерности изменения содержания $\mathrm{P}_{2} \mathrm{O}_{5}$ по мощности пласта проводилось методом корреляционного анализа данных опробования и результатов химических анализов, выполненных Управлением геологии ЭССР. В общей сложности объем статистического материала составили данные 3280 керновых проб по 421 скважине, пробуренной в ходе предварительной и детальной разведок месторождения за период с 1966 по 1971 ғ.

Предварительно было изучено распределение содержания компонентов по горизонтальным сечениям пласта от подошвы до кровли с интервалом между сечениями 0,5 м. Кривые, построенные по полученным данным на рис. 1 в аксонометрии, дают общее представление о пространственном (объемном) распределении $\mathrm{P}_{2} \mathrm{O}_{5}$ в пласте. Координатами пространственного распределения являются содержание, мощность пласта и частота наблюдений. Как видно из рис. 1, содержание 


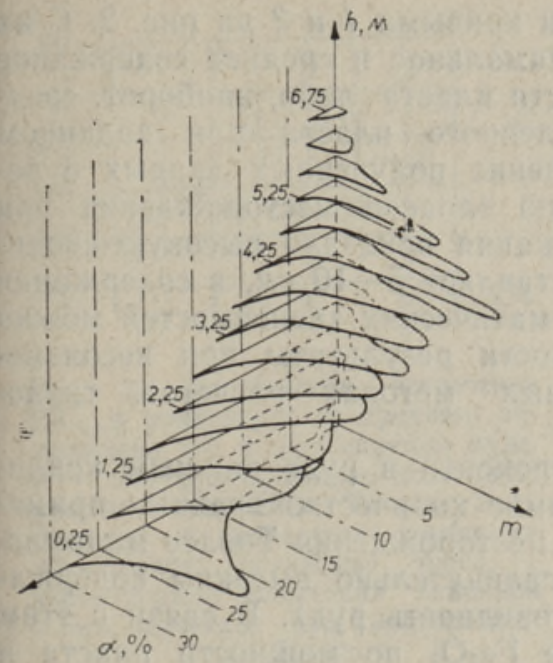

Рис. 1. Объемное распределение содержания $\mathrm{P}_{2} \mathrm{O}_{5}$ в пласте. $h$ - мощность пласта, $\alpha-$ содержание $\mathrm{P}_{2} \mathrm{O}_{5}, m$ - частота наблюдений, 0,25-6,75 - высота сечения от подошвы пласта, $\mu$.

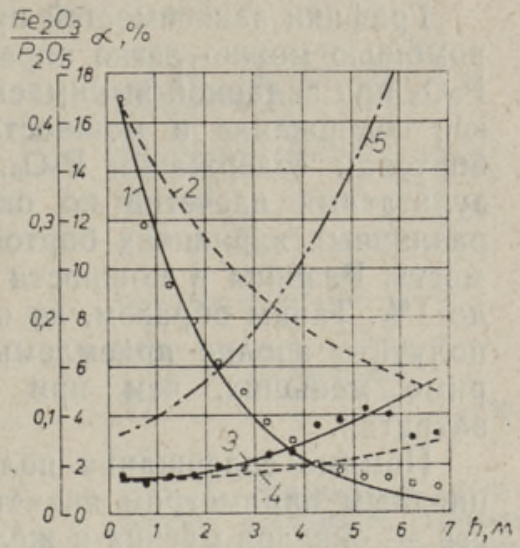

Рнс. 2. Распределение компонентов по мощности пласта. 1 и 2 соответственно бортовое и среднее содержание $\mathrm{P}_{2} \mathrm{O}_{5}, 3$ и 4 - соответственно бортовое и среднее содержание $\mathrm{Fe}_{2} \mathrm{O}_{3}, 5-$ соотношение средних содержаний $\mathrm{Fe}_{2} \mathrm{O}_{3}$ и $\mathrm{P}_{2} \mathrm{O}_{5}$.

$\mathrm{P}_{2} \mathrm{O}_{5}$ и размах его колсбаний уменьшаются от подошвы пласта к кровле, однако коэффициент вариации по сечениям изменяется незначительно $(0,4-0,6)$, и это изменение противоположно по направлению, т. е. в нижних сечениях пласта содержание более стабильно, чем в верхних. По всем сечениям распределение близко к логарифмическинормальному, лишь в нижнем наблюдается двумодальное распределение с максимальной частотой при содержании $\mathrm{P}_{2} \mathrm{O}_{5} 22 \%$ и с некоторым повышением частоты наблюдений при 5-7\%. Статистические характеристики содержания $\mathrm{P}_{2} \mathrm{O}_{5}$ в целом по пласту были следующими: среднее значение $7,63 \%$, среднеквадратичное отклонение 6,27 и коэффициент вариации 0,82 .

Аппроксимация взаимосвязи содержания $\mathrm{P}_{2} \mathrm{O}_{5}$ и мощности пласта проводилась экспоненциальной, параболической и степенной зависимостями. Наиболее подходящей оказалась экспоненциальная зависимость, выражающаяся уравнением регрессии:

$$
\alpha=16,99 \exp \left(-\frac{h+0,5}{2}\right),
$$

где $\alpha$ - средневзвешенное содержание $\mathrm{P}_{2} \mathrm{O}_{5}$ в сечении пласта, $\%$; $h$ - расстояние от подошвы пласта до сечения, $\boldsymbol{M}$.

Зависимость характеризуется высокой теснотой связи, индекс корреляции составляет 0,847 .

Рассматривая содержание $\mathrm{P}_{2} \mathrm{O}_{5}$ в сечении как бортовое и расстояние от подошвы пласта до сечения как вынимаемую мощность, среднее содержание в пласте легко определить из выражения:

$$
\alpha(h)=\frac{16,99}{h} \int_{0}^{h} e^{-\frac{h+0,5}{2}} d h .
$$


Графики зависимостей представлены кривыми 1 и 2 на рис. 2. С их помощью можно легко определить минимальное и среднее содержание $\mathrm{P}_{2} \mathrm{O}_{5}$ при заданной вынимаемой мощности пласта либо, наоборот, среднее содержание и мощность промышленного пласта при заданном бортовом содержании $\mathrm{P}_{2} \mathrm{O}_{5}$. Сопоставление полученных данных с результатами расчетов по оконтуриванию запасов месторождения при различных вариантах бортового содержания показало высокую сходимость. Разница в мощности пласта составляет 5-10 cM, в содержании до $1 \%$. Таким образом, на основе математических зависимостей можно получить вполне приемлемые по точности результаты при несоизмеримо меньших, чем при традиционных методах расчетов, трудозатратах.

Помимо содержания полезного компонента в руде важным кондиционным параметром является допустимое количество вредных примесей - окислов магния и железа. Руды месторождения Тоолсе маломагнезиальные, однако характеризуются сравнительно высоким содержанием $\mathrm{Fe}_{2} \mathrm{O}_{3}$ (особенно железистая разновидность руд). В связи с этим нами было исследовано распределение $\mathrm{Fe}_{2} \mathrm{O}_{3}$ по мощности пласта и его взаимосвязь с содержанием $\mathrm{P}_{2} \mathrm{O}_{5}$. Исходным материалом при этом служили данные 2416 керновых проб. Установлено, что распределение содержания $\mathrm{Fe}_{2} \mathrm{O}_{3}$ по мощности описывается уравнением параболы (при индексе корреляции 0,570$)$ :

$$
\alpha=1,326+0,058 h+0,083 h^{2} .
$$

По аналогии с вышеизложенным определено также среднее содержание $\mathrm{Fe}_{2} \mathrm{O}_{3}$ в зависимости от вынимаемой мощности пласта (рис. 2, кривые 3 и 4). Изменение содержания $\mathrm{Fe}_{2} \mathrm{O}_{3}$ не столь интенсивно и имеет противоположный распределению $\mathrm{P}_{2} \mathrm{O}_{5}$ характер. Таким образом, по мере увеличения вынимаемой мощности пласта возрастает отношение содержаний $\mathrm{Fe}_{2} \mathrm{O}_{3}$ и $\mathrm{P}_{2} \mathrm{O}_{5}$ (кривая 5 на рис. 2). Например, при увеличении мощности от 3 до 4 м отношение возрастает от 0,185 до 0,255 . Если исходить из рекомендуемого ГИГХС'ом максимально допустимого отношения $-0,2$, то вынимаемая мощность пласта составит $3,2 м$ при бортовом и среднем содержании $\mathrm{P}_{2} \mathrm{O}_{5}$ соответственно 3,5 и $8,8 \%$. При снятии этого ограничения мощность выемки может быть увеличена.

От выбора бортового содержания $\mathrm{P}_{2} \mathrm{O}_{5}$ зависят не только среднее содержание и вынимаемая мощность пласта, но и степень извлечения геологических запасов $\mathrm{P}_{2} \mathrm{O}_{5}$ как по сырой руде, так и в пересчете на концентрат. Последнее связано не только с потерями $\mathrm{P}_{2} \mathrm{O}_{5}$ в недрах, но и с изменением извлечения его в концентрат при обогащении в зависимости от качества исходной руды.

До сих пор отсутствует достаточное количество данных об обогатимости руд месторождения Тоолсе. Известны лишь данные лабораторных и полупромышленных испытаний, выполненных ГИГХС'ом - Цуцульковский и др., 1972; Селиванова и др., 1973), и фактические данные по обогащению руд аналогичного состава в комбинате «Фосфорит» (Левин и др., 1979). Обработка имеющихся данных позволила нам установить наличие линейной взаимосвязи (рис. 3) между извлечением $\mathrm{P}_{2} \mathrm{O}_{5}$ в концентрат $(\varepsilon)$ и содержанием его в поступающей на обогащение руде $(\alpha)$, описанной уравнением регрессии (при коэффициенте корреляции 0,593$)$ :

$$
\varepsilon=71,7+1,052 \alpha
$$




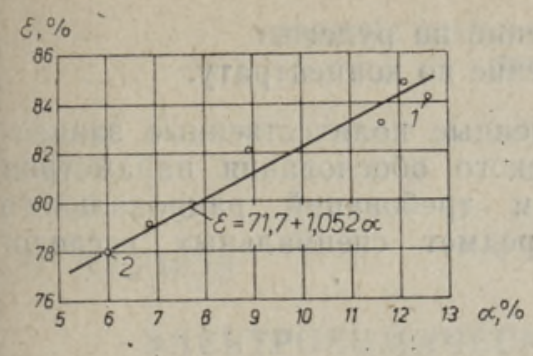

Рис. 3. Зависимость извлечения $\mathrm{P}_{2} \mathrm{O}_{5}$ в концентрат от среднего содержания его в обогащаемой руде. 1 - полупромышленные испытания руд месторождения Тоолсе, 2 фактические показатели комбината «Фосфорит»; остальные точки лабораторные испытания анионной схемы флотации руд месторождения Тоолсе.

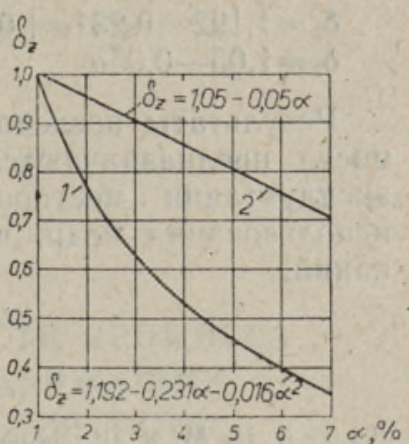

Рис. 4. Зависимость показателя извлечения запасов от бортового содержания $\mathrm{P}_{2} \mathrm{O}_{5}$ в массиве: 1 - по сырой руде, 2 - по $28 \%$-ному концентрату.

Товарный выход концентрата в зависимости от содержания $\mathrm{P}_{2} \mathrm{O}_{5}$ в обогащаемой руде и в концентрате можно определить как:

$$
\gamma=\frac{\alpha \varepsilon}{100 \alpha_{k}}=\frac{71,7 \alpha+1,052 \alpha^{2}}{100 \alpha_{k}}
$$

где $\gamma$ - выход концентрата в долях единицы;

$\alpha$ и $\alpha_{k}$ - содержание $\mathrm{P}_{2} \mathrm{O}_{5}$ соответственно в руде и в концентрате, \%

C учетом отмеченных зависимостей было исследовано изменение извлечения общих геологических запасов месторождения в зависимости от величины бортового содержания $\mathrm{P}_{2} \mathrm{O}_{5}$. За основу был принят линейный запас, выражаемый объемом извлекаемого полезного ископаемого на $1 M^{2}$ площади месторождения. В угольной промышленности этот показатель принято называть производительностью пласта, на россыпных месторождениях - продуктивностью россыпи. Использование его при оценке извлечения запасов обширных по площади пластовых месторождений вполне правомерно и распространенно (Матерон, 1968; Наbicht, 1961). Линейный запас в объемном исчислении равен вынимаемой мощности пласта, в исчислении по массе - произведению вынимаемой мощности и плотности полезного ископаемого.

Результаты расчетов, показанные на рис. 4, характеризуют относительное изменение извлечения в зависимости от бортового содержания $\mathrm{P}_{2} \mathrm{O}_{5}$. За базис приняты запасы, ограниченные по мощности выемки бортовым содержанием $1 \%$ и условно рассматриваемые как геологические. Из рис. 4 видно, что по мере увеличения бортового, а следовательно, и среднего содержаний $\mathrm{P}_{2} \mathrm{O}_{5}$ извлечение запасов снижается. Одновременно с этим возрастают извлечение полезного компонента в концентрат при обогащении и выход концентрата на единицу руды, что делает неодинаковой степень изменения исследуемого показателя в расчете на сырую руду и на концентрат. Например, при увеличении бортового содержания $\mathrm{P}_{2} \mathrm{O}_{5}$ от 1 до $7 \%$ извлечение руды снижается от 1 до 0,345, в то время как в пересчете на $28 \%$-ный концентрат снижается только до 0,701 .

В рассмотренном диапазоне изменения бортового содержания показанные на рис. 4 расчетные графики достаточно точно описываются линейной и параболической зависимостями вида; 


$$
\begin{array}{ll}
\delta_{z}=1,192-0,231 \alpha+0,016 \alpha^{2} & \text { - извлечение по руде; } \\
\delta_{z}=1,05-0,05 \alpha & \text { - извлечение по концентрату. }
\end{array}
$$

Результаты исследований и установленные количественные зависимости предназначаются для экономического обоснования параметров эксплуатации месторождения с учетом требований рационального использования недр, что составляет предмет специальных исследований.

\section{ЛИТЕРАТ У РА}

Л е в и н И. М. и др. Экономическая оценка схем обогащения бедных фосфатных руд с целью получения высококачественных концентратов, пригодных для химической переработки. - Обзорн. инф. серия «Гөрнохимическая промышленность». М., 1979.

М а те рон Ж. Основы прикладной геостатистики. М., 1968.

Р а у д с еп Р. Вещественный состав фосфоритоносных пород месторождения Тоолсе. Изв. АН ЭССР. Хим. Геол., 1975, 24, 137-144.

Сели в анов а И. С. и др. Флотация фосфоритов новых эстонских месторождений. - Тр. ГИГХС, 1973, вып. 20, 78-85.

$\checkmark$ Цуцульковски й В. Я. и др. Обогащение основных типов руд месторождения Тоолсе. - Химическая промышленность, 1972, 9, 43-44.

$\mathrm{Habicht,} \mathrm{K.} \mathrm{Eesti} \mathrm{NSV} \mathrm{fosforiidivarude} \mathrm{kasutamise} \mathrm{majandusliku} \mathrm{tasuvuse} \mathrm{määra-}$ mise metoodika. - ENSV TA Toim. Ohisk., 1961, 10, 104-112.
Ннститут экономики
Академии наук Эстонской ССР
Поступила в редакцию $18 / \mathrm{V} 1981$

R. PASOK

\section{TOOLSE LEIUKOHA FOSFORIIDIMAAGI KOMPONENTIDE JAOTUSE SEADUSPÄRASUSTE SEOS MAAVARA SAAGISEGA}

Korrelatsioonanalüüsi meetodil on uuritud $\mathrm{P}_{2} \mathrm{O}_{5}$ ja $\mathrm{Fe}_{2} \mathrm{O}_{3}$ jaotust fosforiidikihi vertikaallõikes, määratud kindlaks regressioonsōltuvus kihi väljamispaksuse ja komponentide piir- ja keskmise sisalduse vahel ning leitud fosforiidimaagi kadude analüütiline sōltuvus $\mathrm{P}_{2} \mathrm{O}_{5}$ piirsisaldusest.

\section{R. PASOK}

\section{AN INVESTIGATION OF THE REGULARITIES IN THE DISTRIBUTION OF ORE COMPONENTS IN THE TOOLSE DEPOSIT AND THEIR INTERDEPENDENCE AT THE EXTRACTION OF RESOURCES}

Using the method of correlation analysis, the distribution of $\mathrm{P}_{2} \mathrm{O}_{5}$ and $\mathrm{Fe}_{2} \mathrm{O}_{3}$ in the thickness of the horizontal phosphorite deposit was studied. Regressive interdependence between the excavable thickness, the boundary and average contents of components was established. Analytical dependence of the coefficient variation of extraction of the resources upon the boundary content of $\mathrm{P}_{2} \mathrm{O}_{5}$ is presented. 